\title{
CORRECTIONS
}

\section{Intravenous fluid therapy for adults in hospital: summary of NICE guidance}

In this Practice article by Smita Padhi and colleagues (BMJ 2013;347:f7073, doi:10.1136/bmj.f7073) the figure (algorithms for intravenous fluid therapy) contained an error. In algorithm 3 the normal requirements of sodium, potassium, and chloride should read $1 \mathrm{mmol} / \mathrm{kg} /$ day [not $1 \mathrm{mmol} / \mathrm{L} / \mathrm{kg} /$ day]. The correct figure is provided here. $\downarrow$

Cite this as: BMJ 2013;346: 17624

๑ BMJ Publishing Group Ltd 2013 


\section{Figure}

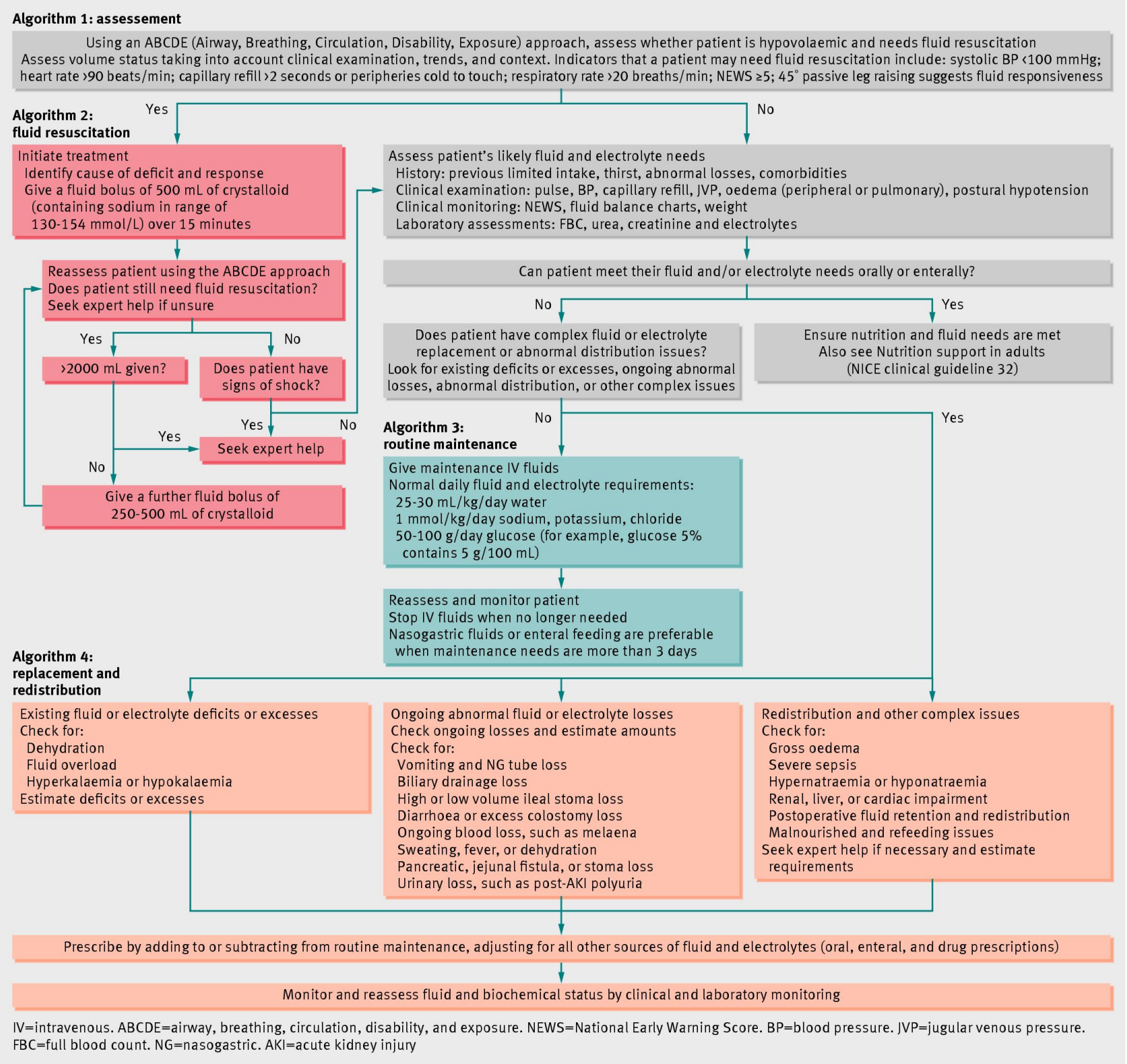

